\title{
Precise aftershock distribution of the 2007 Chuetsu-oki Earthquake obtained by using an ocean bottom seismometer network
}

\author{
Masanao Shinohara ${ }^{1}$, Toshihiko Kanazawa ${ }^{1}$, Tomoaki Yamada ${ }^{1}$, Kazuo Nakahigashi ${ }^{1}$, Shin'ichi Sakai ${ }^{1}$, Ryota Hino ${ }^{2}$, \\ Yoshio Murai ${ }^{3}$, Akira Yamazaki ${ }^{4}$, Koichiro Obana ${ }^{5}$, Yoshihiro Ito ${ }^{2}$, Kazuhiro Iwakiri $^{4}$, Ryo Miura ${ }^{3}$, Yuya Machida ${ }^{3}$, \\ Kimihiro Mochizuki ${ }^{1}$, Kenji Uehira ${ }^{6}$, Michitaka Tahara ${ }^{6}$, Asako Kuwano ${ }^{1}$, Shin'ichiro Amamiya ${ }^{3}$, \\ Shuichi Kodaira ${ }^{5}$, Tetsuo Takanami ${ }^{3}$, Yoshiyuki Kaneda ${ }^{5}$, and Takaya Iwasaki ${ }^{1}$ \\ ${ }^{1}$ Earthquake Research Institute, University of Tokyo, Tokyo 113-0032, Japan \\ ${ }^{2}$ Graduate School of Science, Tohoku University, Sendai 980-8578, Japan \\ ${ }^{3}$ Institute of Seismology and Volcanology, Hokkaido University, Sapporo 060-0810, Japan \\ ${ }^{4}$ Meteorological Research Institute, Japan Meteorological Agency, Tsukuba 305-0052, Japan \\ ${ }^{5}$ Japan Agency for Marine-Earth Science and Technology, Yokosuka 237-0061, Japan \\ ${ }^{6}$ Institute of Seismology and Volcanology, Kyushu University, Shimabara 855-0843, Japan
}

(Received December 6, 2007; Revised March 25, 2008; Accepted March 28, 2008; Online published November 18, 2008)

\begin{abstract}
The Chuetsu-Oki Earthquake occurred on July 16, 2007. To understand the mechanism of earthquake generation, it is important to obtain a detailed seismic activity. Since the source region of the 2007 Chuetsu-oki Earthquake lies mainly offshore of Chuetsu region, a central part of Niigata Prefecture, it is difficult to estimate the geometry of faults using only the land seismic network data. A precise aftershock distribution is essential to determine the fault geometry of the mainshock. To obtain the detailed aftershock distribution of the 2007 Chuetsu-oki Earthquake, 32 Ocean Bottom Seismometers (OBSs) were deployed from July 25 to August 28 in and around the source region of the mainshock. In addition, a seismic survey using airguns and OBSs was carried out during the observation to obtain a seismic velocity structure below the observation area for precise hypocenter determination. Seven hundred and four aftershocks were recorded with high spatial resolution during the observation period using OBSs, temporally installed land seismic stations, and telemetered seismic land stations and were located using the double-difference method. Most of the aftershocks occurred in a depth range of 6-15 km, which corresponds to the 6-km/s layer. From the depth distribution of the hypocenters, the aftershocks occurred along a plane dipping to the southeast in the whole aftershock region. The dip angle of this plane is approximately $40^{\circ}$. This single plane with a dip to the southeast is considered to represent the fault plane of the mainshock. The regions where few aftershocks occurred are related to the asperities where large slip is estimated from the data of the mainshock. The OBS observation is indispensable to determine the precise depths of events which occur in offshore regions even close to a coast.
\end{abstract}

Key words: 2007 Chuetsu-oki Earthquake, aftershock distribution, fault geometry, ocean bottom seismometer (OBS).

\section{Introduction}

The Niigata-ken Chuetsui-oki Earthquake in 2007 $\left(M_{\mathrm{j}} 6.8\right)$ occurred at a shallow depth near the central coast of Niigata Prefecture, Japan, on July 16, 2007, and strongly shook the region of the Niigata and Nagano Prefectures, with a maximum seismic intensity of an upper 6 on the Japan Meteorological Agency (JMA) scale, causing large damage. Many aftershocks occurred following the mainshock. The magnitude of the largest aftershock that occurred on the same day as the mainshock is 5.8. Prior to the mainshock, two large earthquakes (the Chuetsu Earthquake, $M_{\mathrm{j}} 6.8,2004$; the Noto-Hanto Earthquake, $M_{\mathrm{j}} 6.9$, 2007) had occurred in the coastal area of the Japan Sea in central Japan (Fig. 1). The source region of the Chuetsu-oki Earthquake lies mainly under an offshore region that stretches

Copyright (C) The Society of Geomagnetism and Earth, Planetary and Space Sciences (SGEPSS); The Seismological Society of Japan; The Volcanological Society of Japan; The Geodetic Society of Japan; The Japanese Society for Planetary Sciences; TERRAPUB. from a few kilometers to $15 \mathrm{~km}$ off the coast of the Chuetsu region. Although it was estimated using land seismic networks that the mainshock has a thrust-type focal mechanism with a compressional axis of northwest-southeast, it is difficult to estimate an exact focal plane geometry using only the land seismic networks. A precise aftershock distribution is needed to define the geometry of the mainshock fault. In addition, this kind of information is useful for studies of earthquake generation and tectonics in this region. The precise determination of aftershock distribution is difficult using only land seismic network data when the source region is positioned under an offshore area near a coast line. It is widely known that an ocean bottom seismometer (OBS) observation is essential to obtain a high-resolution aftershock distribution associated with large earthquakes that occurred in the marine environment (e.g., Shinohara et al., 2004; Sakai et al., 2005; Yamada et al., 2005). In addition, a spatially dense OBS observation is also necessary for a precise distribution of aftershocks occurring near a coast line be- 


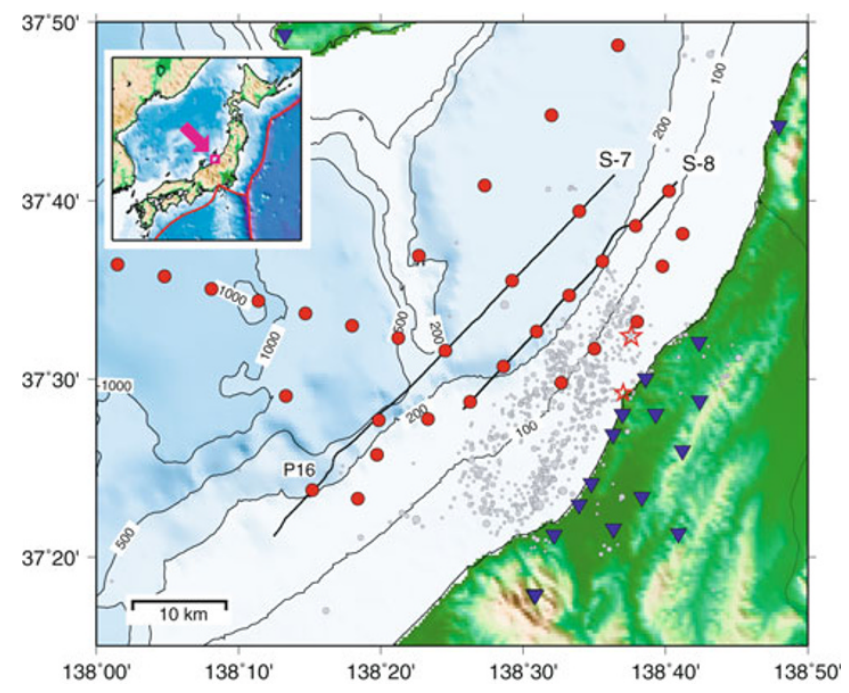

Fig. 1. Location map of ocean bottom seismometers and land seismic stations used for this study. Bathymetric contours indicate water depths of $100,200,500$, and $1000 \mathrm{~m}$. Circles indicate the positions of pop-up type OBSs. Inverted triangles denote the position of land seismic station used for this study. Small gray circles denote epicenters of aftershocks determined by the Japan Meteorological Agency from July 26 to August 24, 2007. Large and small stars indicate the epicenters of the mainshock and the largest aftershock, respectively. The mainshock and the largest aftershock were relocated by Sakai et al. (in preparation) using permanent telemetered land seismic stations. Thick lines labeled as S-7 and S-8 indicate the profiles of the seismic refraction/structural survey during the KR07-E01 research cruise. P16 indicates the number of OBS in Fig. 2. Inset is the index map of the study area. Arrow and rectangle show the location of the study area.

cause a seismic network must cover a whole source region (Uehira et al., 2006; Yamada et al., 2008).

Nine days after the mainshock, we started the aftershock observation using pop-up type OBSs in order to obtain detailed aftershock lateral and depth distributions of the 2007 Chuetsu-oki Earthquake. We deployed 32 OBSs for a period of 1 month in the high-activity aftershock region of the mainshock. A large number of temporary land seismic stations were also deployed in the vicinity of the source region by the "Group for the Aftershock Observations of the 2007 Niigata-ken Chuetsu-oki Earthquake" (Kato et al., 2008; Sakai et al., in preparation). This paper describes the OBS observations and the precise aftershock distribution, with particular focus on the depths of the events, using pop-up OBSs in the whole aftershock area combined with a part of land seismic stations. Using the precise aftershock distribution determined by the dense OBS network, we discuss the geometry of the fault of the 2007 Chuetsu-oki Earthquake.

\section{Observations}

The M/V Kaiko-maru No. 12 (Offshore Operation Co., chartered by Earthquake Research Institute (ERI), University of Tokyo) was used to deploy the OBS (Fig. 1) and was completed on July 26. From August 18 to 28, all of the OBSs were successfully recovered during the KR07E01 research cruise of the R/V Kairei operated by the Japan Agency for Marine-Earth Science and Technology (JAMSTEC). A seismic survey using airguns and shortperiod OBSs was also carried out during the KR07-E01 cruise to obtain seismic velocity structures in the observation area to be used for precise hypocenter determination. The OBSs for aftershock observation also recorded airgun signals. Airguns were shot on two profiles parallel to the coast (S-7 and S-8 in Fig. 1). The total capacities of the airguns were 200 liters and 100 liters for profile S-7 and profile S-8, respectively. The shooting intervals were approximately $230 \mathrm{~m}$ and $150 \mathrm{~m}$ for $\mathrm{S}-7$ and $\mathrm{S}-8$, respectively.

The observation area is $50 \times 40 \mathrm{~km}$ and covers the area of high aftershock activity and the northwestern area from the source region where no permanent seismic station is installed. The OBS interval was approximately $5 \mathrm{~km}$ in the source region in order to obtain spatially dense data. The depth of the water in the source region is 100-200 m. In the seaward area, OBSs were deployed at intervals of about $10 \mathrm{~km}$ because this region had little aftershock activity. In the southwestern part of the source region, no OBS was deployed in consideration of local fishery activities.

All of the deployed OBSs had nearly the same configuration. Thirty OBSs have one vertical and two horizontal velocity-sensitive electro-magnetic geophones with a natural frequency of $4.5 \mathrm{~Hz}$ and the others use three-component $2-\mathrm{Hz}$ velocity geophones. The resolution of the A/D conversion is 16 bits or 24 bits. Accurate timing, estimated to be within $0.05 \mathrm{~s}$, is provided by a crystal oscillator. All of the OBSs are a pop-up type with an acoustic release system. The positions of the OBSs on the sea floor were based on the deployment positions measured using the ship's GPS because of the shallow depth of the water. We also determined exact water depth of the OBSs by acoustic ranging. For some OBSs, the positions on the sea floor and the accuracy of timing were confirmed by the travel times of waterdirect waves from the airguns. The accuracy of the OBS positions on the sea floor is estimated to be tens of meters. The land seismic stations used for this study consist of 12 temporal seismic stations installed by ERI, University of Tokyo (Kato et al., 2008; Sakai et al., in preparation) and four permanent telemetered land seismic stations.

\section{Data and Hypocenter Determination}

We used waveform data from the OBSs and several land seismic stations. We selected 715 events which the JMA had determined using the data of the permanent telemetered land seismic network operated by the National Research Institute for Earth Science and Disaster Prevention (NIED), JMA, and universities (the JMA unified hypocenter cata$\log$ ). Data from all OBSs and land stations were combined into multistation waveform data files for each event. $P$ and $S$-wave arrival times were picked on a computer display (Urabe and Tsukada, 1991).

Precise velocity structure in the study region is essential for accurate hypocenter location. We have two profiles for seismic structure during the KR07-E01 cruise. First, we made record sections of the airguns for the OBSs below the profiles (Fig. 2). All the record sections of the OBSs have similar characteristics. In the vertical component record sections, the apparent velocity of first arrivals at distances up to $20 \mathrm{~km}$ gradually increases and is $6.0-6.3 \mathrm{~km} / \mathrm{s}$ at distances greater than $20 \mathrm{~km}$ (Fig. 2). One-dimensional (1-D) $P$-wave velocity structure in a shallow region just below 

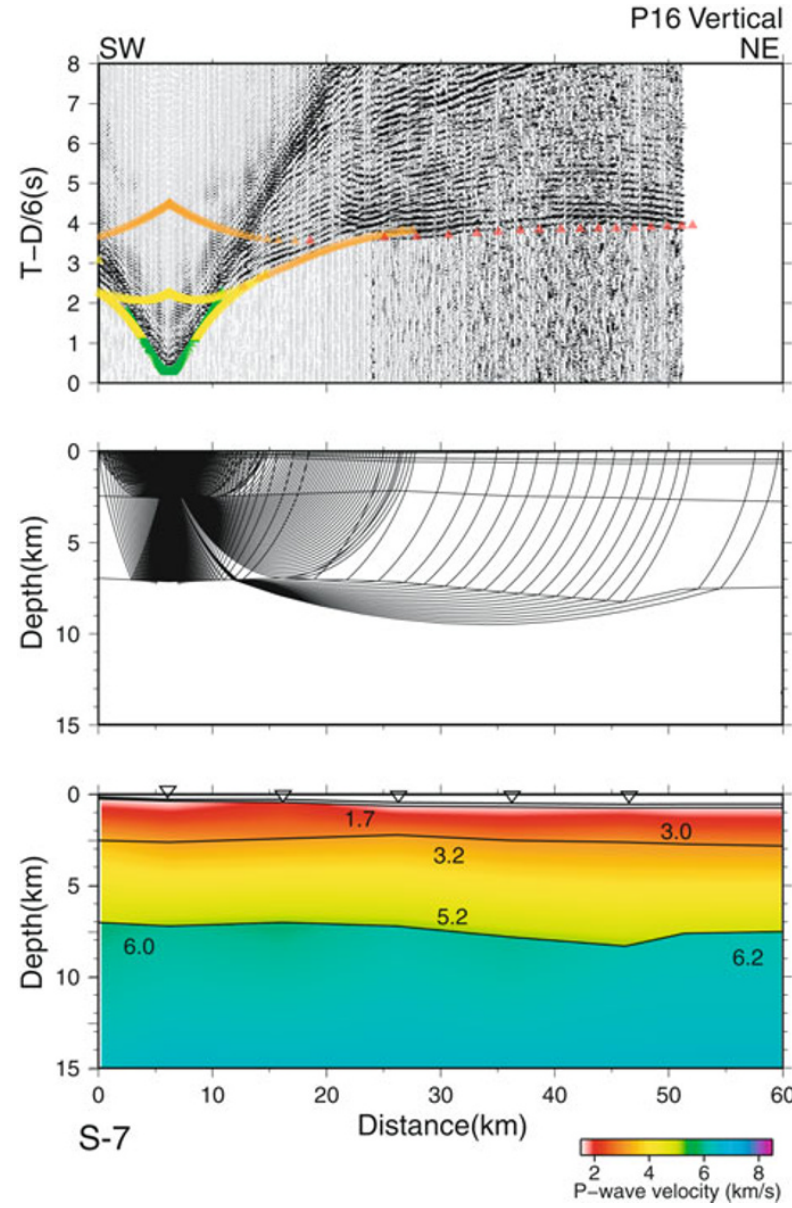

Fig. 2. Top: Observed airgun signals recorded by OBS P-16 on the profile S-7, vertical component. A band-pass filter $(3-15 \mathrm{~Hz})$ was applied to the observed data. Each trace is normalized to its maximum amplitude. Reduction velocity is $6 \mathrm{~km} / \mathrm{s}$. Symbols indicate the estimated travel time from the final velocity model. Middle: Ray diagram for P-16 calculated using the final velocity model. Ray paths cover the sedimentary layers and top of the $6-\mathrm{km} / \mathrm{s}$ layer. Bottom: Final $P$-wave velocity model derived by 2-D ray tracing method. Numerals are $P$-wave velocities in $\mathrm{km} / \mathrm{s}$. The velocities are also color-coded. Inverted triangles at the top indicate the positions of OBSs on the profile S-7.

each OBS was obtained by $\tau$-p method (Shinohara et al., 1994). The set of 1-D $P$-wave velocity structure just below each OBS was used to construct an initial model for the 2-D ray tracing method (Zelt and Smith, 1992). We used a trial-and-error method to obtain a 2-D velocity model that can explain the observed travel times of first and later arrivals for all the OBS on the profiles (Fig. 2). The estimated velocity structures below the profiles have a little lateral heterogeneity. The shallow structure can be divided into two layers based on the velocities and vertical velocity gradient: the upper and lower layers have $P$-wave velocities of $1.7-$ $3.0 \mathrm{~km} / \mathrm{s}$ and $3.1-5.3 \mathrm{~km} / \mathrm{s}$, respectively. The total thickness of the shallow layers is approximately $7 \mathrm{~km}$, and these layers have a large vertical velocity gradient. A layer with a $P$-wave velocity of $6.2 \mathrm{~km} / \mathrm{s}$ exists below the shallow layers and is relatively homogeneous vertically. We constructed a simple seismic structure based on the results of the seismic structural surveys to be used for the hypocenter locations (Fig. 3). Since we obtained no information for the region deeper than $10 \mathrm{~km}$ from the seismic surveys, we adopted a

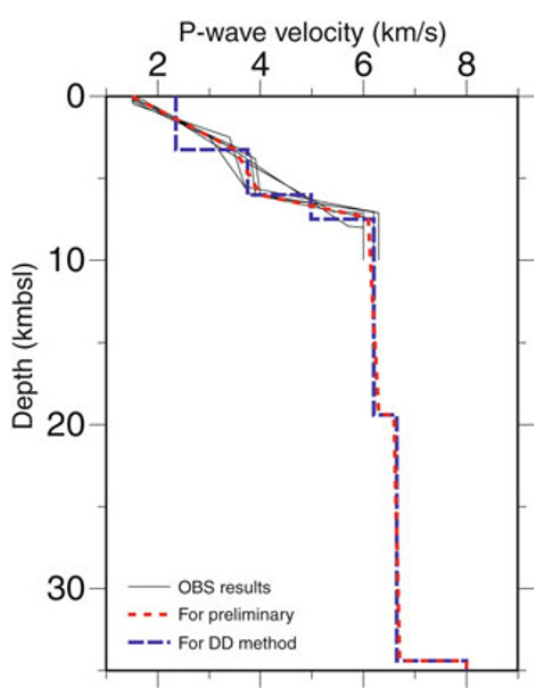

Fig. 3. $P$-wave velocity structure models for the hypocenter determination. Thin solid lines indicate the estimated velocity structure just below OBSs. The red dotted line and blue dotted line denote the $P$-wave velocity models for the preliminary location and the double-difference method, respectively. The models are derived from the refraction experiment carried out using the OBSs during the aftershock observation.

velocity structure that is used for the routine hypocenter determination at ERI, University of Tokyo. We also assumed that the ratio of $P$-wave to $S$-wave velocity is 1.73 . Since the thickness and velocity of the uppermost layers changes at each OBS site, the estimated travel times by the location program must be corrected.

Preliminary hypocenter locations were determined by the maximum-likelihood estimation technique of Hirata and Matsu'ura (1987). Because of the uncertainty in the sedimentary layer in terms of thickness and seismic velocity, we used the following method. First, we located the hypocenter using $P$ - and $S$-wave arrival times with assumed station correction values for the used velocity structure. Averaged differences between observed travel time and estimated travel times (O-C times) for each station were calculated. The averaged $\mathrm{O}-\mathrm{C}$ times were added to the previous station correction values, and the hypocenters were relocated. We repeated this procedure two times. After this procedure, the averaged $\mathrm{O}-\mathrm{C}$ times become less than $0.1 \mathrm{~s}$ for both the $P$-wave and $S$-wave. Finally, hypocenters were relocated by the double-difference (DD) method (Waldhauser and Ellsworth, 2000). We reconstructed a velocity structure for the DD method (Fig. 3) because the DD method accepts an 1-D structure where each layer has a constant velocity. A velocity of each layer for the DD method was determined based on the velocity structure for the preliminary location. Magnitudes of the aftershocks were estimated using the maximum amplitudes of the data recorded by the land array (Watanabe, 1971).

The OBS and land station network located 704 earthquakes using the DD method (Fig. 4). During the preliminary location, errors of each aftershock location were calculated from the total covarience matrix of the location program (Hirata and Matsu'ura, 1987). As a result, the aftershocks whose epicenters are within our network have small errors, thereby confirming the potential to precisely 

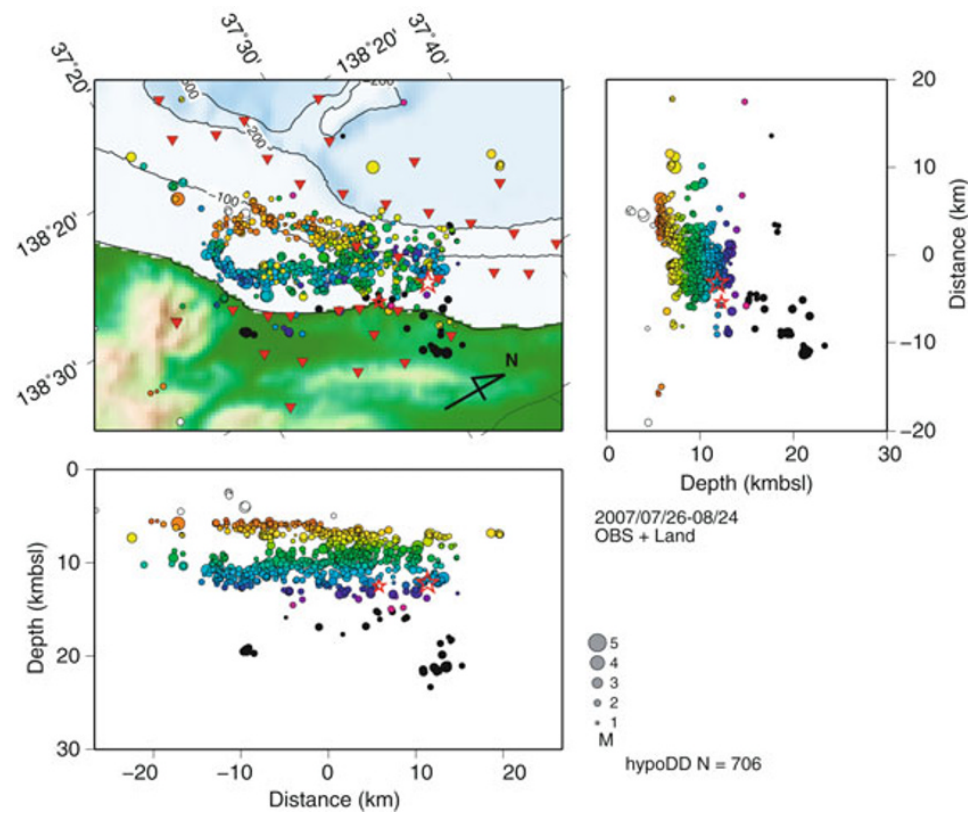

Fig. 4. Final hypocenter distribution (July 26-August 24, 2007) arrived at using the double-difference method with bathymetry. The inverted triangles indicate the positions of the pop-up type OBSs and the land seismic station used for this study. The circles filled with color represent hypocenters. The depth of events are color-coded. The diameters of the circles are proportional to the magnitudes. Large and small stars indicate the positions of the mainshock and the largest aftershock, respectively. Contours indicate water depths of 100, 200, and 500 m. In the vertical section, the concentration of the aftershocks in depths of 6-15 km is clearly recognized. From the NW-SE vertical cross section, the aftershocks become deeper to the southeastward.

locate aftershocks. Average location errors are approximately $0.1 \mathrm{~km}$ in the horizontal direction and about $0.3 \mathrm{~km}$ in depth. In other words, the resolution of the hypocenter is considerably high within our seismic network.

\section{Results}

Figure 4 shows the high-resolution locations of aftershocks of the 2007 Chuetsui-oki Earthquake. Most of the aftershocks occurred at depths ranging from $6 \mathrm{~km}$ to $15 \mathrm{~km}$ and under the offshore area. The epicenters of most of the aftershocks are distributed in an area of $28 \times 10 \mathrm{~km}$. In general, aftershocks that are positioned in the northwestern part are shallower than those in the southeastern part. Seismic activity in the aftershock area did not change appreciably in terms of number or magnitude of events over the duration of the observation. The epicenter distribution is not uniform, even in the high activity region of $28 \times 10 \mathrm{~km}$. In the southwestern part of the source region, epicenters form a doughnut-shape. The existence of the low-seismicity region in the southwestern part of the source area (the center of the doughnut shape) is confirmed because the location errors of the aftershocks are enough small (less than $1 \mathrm{~km}$ in the horizontal direction). On the other hand, epicenters are distributed homogeneously in the northeastern area. The aftershock region below the southwestern part is a few kilometers shallower than those in the northeastern area. The earthquakes with a depth greater than $18 \mathrm{~km}$ are limited to the easternmost area of the aftershock area.

\section{Discussion}

The hypocenters determined by the OBS and land station network correspond to those determined by the JMA from the permanent land seismic network (the JMA unified hypocenter catalog). Here, we compare our results to those reported by the JMA. Although most of the hypocenters reported by the JMA in the study region have depths greater than $15 \mathrm{~km}$, most of those determined by our network have focal depths of less than $15 \mathrm{~km}$. This indicates that the depths of events determined by using only the land seismic network data have a large uncertainty for events occurring offshore. Because our OBS and land station network covered the whole aftershock area, a high resolution of depth is obtained for each event. The absolute depth of each event depends on the velocity structure used for the hypocenter location. In this study, we adopt the velocity structure estimated by the seismic survey. Since the hypocenter location program is based on a 1-D structure with a constant $V_{p} / V_{s}$ ratio (1.73), the travel times estimated by the location program were corrected at each OBS station for local heterogeneity, such as a thickness change of the sedimentary layers. Additionally, $S$-wave velocities in the location program affect the estimation of the event depth. Because a sedimentary layer below the sea floor generally has a large $V_{p} / V_{s}$ value, a correction value for $S$-wave travel times becomes large. Therefore, it is important to estimate $S$-wave velocities of a sedimentary layer exactly for high-resolution location. We estimated an average $V_{p} / V_{s}$ ratio of the shallow layers whose $P$-wave velocity is less than $5.3 \mathrm{~km} / \mathrm{s}$ based on the travel times of converted waves from the airguns during the seismic structure survey by using the same 1-D velocity location code for the preliminary location. The average $V_{p} / V_{s}$ ratio of 2.2 for the shallow layers is consistent with the correction values for the $S$-wave travel times of the OBSs. Consequently, we estimate that the absolute errors of the event locations are less than $1 \mathrm{~km}$ for both the horizontal position and depth. Since most of the aftershocks 

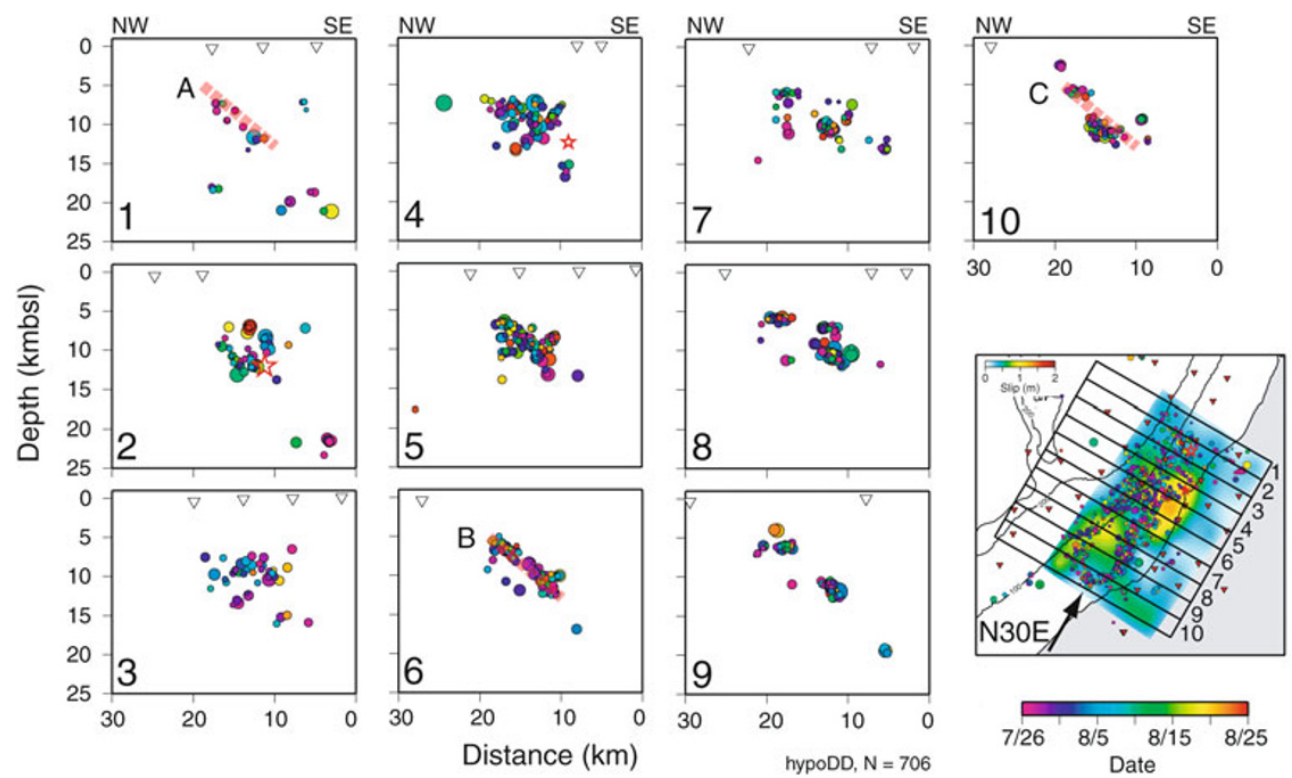

Fig. 5. Vertical cross sections of the aftershocks for ten regions (labeled with numbers). Each vertical section shows the aftershock distribution projected on a vertical plane along the N60W-S120E direction. Each region has a width of $3 \mathrm{~km}$ and a length of $30 \mathrm{~km}$. The colored circles represent hypocenters. The diameters of the circles are proportional to the magnitudes. The filling color indicates the origin time of the event. Large and small stars indicate the positions of the mainshock and the largest aftershock, respectively. The inverted triangles indicate the projected positions of the seismic station used for this study. Dashed lines in sections 1, 6, and 10 indicate the planes formed by the aftershocks. Lines are drawn in the same position for each section and have the same dip angle of $40^{\circ}$. The slip distribution by Koketsu et al. (2007) is also shown in the epicentral distribution (lower right).

have depths greater than $6 \mathrm{~km}$, the high-activity region of the aftershock exists in the $6-\mathrm{km} / \mathrm{s}$ layer.

In cross sections of the hypocentral distribution projected on a vertical plane in the NW-SE direction, we can clearly see the aftershocks form a plane dipping to the southeast in the whole aftershock area (Fig. 5). Although a plane dipping to the southeast is obviously seen in the northernmost part and the southern part of the aftershock area (Fig. 5, sections 1 and 4-10, dashed lines labeled as A and B), there seem to be a few planes in the northern part of the aftershock region (Fig. 5, sections 2-4). In particular, some planes in the northern part have dips to the northwest. However, horizontal lengths of the planes dipping to the northwest are small (less than $3 \mathrm{~km}$ ), and events forming the northwest-dipping plane occurred constantly during the observation time period (Fig. 5). It is thought that a number of events on the NW-dipping decreases with time when the NW-dipping plane was ruptured at the mainshock. Therefore, we interpret that the events which form the NWdipping planes did not occur on the mainshock fault plane. The small areas of the NW-dipping planes are estimated not to make a large contribution to the radiation of seismic energy during the main rupture.

The hypocenter distribution determined by the JMA indicates that there was a possibility that the faults of the mainshock consist of a southeast-dipping plane close to the coast and another plane dipping to the northwest far from the coast in the offshore region. However, the JMA depth resolution of hypocenters located far out at sea becomes poor because the events were located using only land data. In contrast, in our results, there is no NW-dipping plane in the southern area of the source region. This implies that the JMA planes dipping to the northwest far from the coast are apparent because of low resolution of the depths of the location.

The dip angle of the aftershock plane shown in Fig. 5 is approximately $40^{\circ}$. The JMA reports that the mainshock focal mechanism based on polarities of the first arrivals has a SE dip of $37^{\circ}$. Thus, the dip angle of the plane formed by aftershocks is consistent with that of the mainshock mechanism solution. The size of the aftershock area on the SEdipping plane becomes $28 \times 13 \mathrm{~km}$ in consideration of this dip angle. This size of the aftershock region is comparable to the magnitude of the mainshock. The depths of the aftershocks forming the plane gradually become shallow in the southwestern region. However, the dip angle and horizontal position of the planes in each section do not change so large. Therefore, the fault plane of the mainshock may have a distorted shape. In Fig. 5, section 10, the dip angle of a plane (dashed line labeled as C) formed by the events in this section becomes large. Because there are no OBSs above the event in the southernmost region of the aftershock area, there is a possibility that this steep dip of the plane is apparent.

Many investigations of the mainshock source rupture processes of the Chuetsu-oki Earthquake have been carried out using seismic data. For example, Koketsu et al. (2007) used teleseismic $P$-wave and regional strong-motion seismic data and estimated the source process for a fault plane with a NW or SE dip. They concluded that it is difficult to distinguish a dip of the fault plane using only teleseismic data and regional strong-motion data on land. They determined that the maximum dislocation is approximately $1.5 \mathrm{~m}$ and the rupture propagated southwestward. We can compare our results to their result in the case of the southeast dipping plane (Fig. 5). There are a few regions where a large 
slip occurred (asperities) in the aftershock region, similar to some previous large earthquakes that had a few regions where a large slip occurred (e.g. Yamanaka and Kikuchi, 2004). The largest slip region is positioned at the central region of the aftershock area below the coast. Another asperity exists in offshore region of the southern part. A comparison between the aftershock epicenter distribution and the slip distribution clearly reveals that more aftershocks occur outside of the large slip region. In other words, regions where a few aftershocks occurred correspond to the regions of the asperities. This tendency corresponds with the hypothesis of Yamanaka and Kikuchi (2004). These results indicate that precise aftershock distribution is one of indicators of a source rupture process.

\section{Conclusions}

In order to obtain a detailed aftershock distribution of the 2007 Chuetsu-oki Earthquake, 32 OBSs were deployed from July 25 to August 28 in and around the source region of the mainshock. In addition, a seismic survey using airguns and short-period OBSs was carried out during the time period of observation in order to obtain a seismic velocity structure for precise hypocenter determination. In this paper, we present high-spatial resolution locations of the 704 aftershocks derived from joint analysis of the data from the OBSs, temporally installed land seismic stations, and telemetered seismic land stations. For the event locations, we used the velocity structure obtained by the seismic survey conducted during the aftershock observation. Most of the aftershocks are located at depths ranging from $6 \mathrm{~km}$ to $15 \mathrm{~km}$. A comparison of the aftershock distribution to the seismic structure shows that the high activity region of the aftershocks is positioned in the $6-\mathrm{km} / \mathrm{s}$ layer. Cross sections of the hypocentral distribution reveal that the aftershocks form a SE-dipping plane in the whole aftershock region, which we interpret as the fault plane of the mainshock. The dip angle of the plane is consistent with that of the focal solution of the mainshock. A correlation with the slip distribution of the source area indicates that regions with few aftershocks correspond to asperities. The OBS observation is essential to determine the precise depths of events which occur in the marine area even close to a coast.

Acknowledgments. We express our thanks to Dr. N. Takahashi and Mr. T. No for their help in the on-board ship operation for the OBS observation. The work of the officers and crew of $\mathrm{M} / \mathrm{V}$ Kaiko-maru No. 12, R/V Kairei is appreciated. We also thank Messrs. S. Hashimoto, T. Yagi, and K. Uchida for preparation of the OBS observation. The data processing by Ms. H. Hagiwara, Dr. A. Kato and Messrs. M. Kobayashi and S. Watanabe are greatly appreciated. We express our gratitude to Messrs. I. Ogino, K. Miyakawa, and T. Haneda for the installation of the land seismic stations. Drs. K. Koketsu, H. Miyake and K. Hikima kindly provided us with information on the slip distribution. The Niigata Federation of Fisheries Cooperative Associations, Fisheries cooperatives of Teradomari, Izumozaki, and Kashiwazaki, Fishery division of Niigata Prefecture Government cooperated with the OBS observations. A discussion with Dr. N. Hirata was fruitful. Comments by Drs. D. Okaya and A. Nishizawa helped us improve the manuscript. This study is partly supported by the Special
Coordination Funds for the Promotion of Science and Technology (MEXT, Japan), titled as the integrated research for the 2007 Niigata-ken Chuetsu-oki Earthquake. Most of the figures were created using GMT (Wessel and Smith, 1991).

\section{References}

Hirata, N. and M. Matsu'ura, Maximum-likelihood estimation of hypocenter with origin time eliminated using nonliear inversion technique, Phys. Earth Planet. Inter., 47, 50-61, 1987.

Kato, A., S. Sakai, E. Kurashimo, T. Igarashi, T. Iidaka, N. Hirata, T. Iwasaki, T. Kanazawa, and Group for the aftershock observations of the 2007 Niigataken Chuetsu-oki Earthquake, Imaging heterogeneous velocity structures and complex aftershock distributions in the source region of the 2007 Niigataken Chuetsu-oki Earthquake by a dense seismic observation, Earth Planets Space, 60, this issue, 1111-1116, 2008.

Koketsu, K., H. Miyake, and K. Hikima, Source inversion for the 2007 Chuetsu-oki, Japan, earthquake: A case of difficulty determining the source fault plane, Eos Trans. AGU, 88(52), Fall Meet. Suppl., Abstract S54A-05, 2007.

Sakai, S., T. Yamada, M. Shinohara, H. Hagiwara, T. Kanazawa, K. Obana, S. Kodaira, and Y. Kaneda, Urgent aftershock observation of the 2004 off the Kii Peninsula Earthquake using ocean bottom seismometers, Earth Planets Space, 57, 1-6, 2005.

Shinohara, M., N. Hirata, and N. Takahashi, High resolution velocity analysis of ocean bottom seismometer data by the $\tau$-p method, Mar. Geophys. Res., 16, 185-199, 1994.

Shinohara, M., T. Yamada, T. Kanazawa, N. Hirata, Y. Kaneda, T. Takanami, H. Mikada, K. Suyehiro, S. Sakai, T. Watanabe, K. Uehira, Y. Murai, N. Takahashi, M. Nishino, K. Mochizuki, T. Sato, E. Araki, R. Hino, K. Uhira, H. Shiobara, and H. Shimizu, Aftershock observation of the 2003 Tokachi-oki Earthquake by using dense ocean bottom seismometer network, Earth Planets Space, 56, 295-300, 2004.

Uehira, K., T. Yamada, M. Shinohara, K. Nakahigashi, H. Miyamachi, Y. Iio, T. Okada, H. Takahashi, N. Matsuwo, K. Uchida, T. Kanazawa, and H. Shimizu, Precise aftershock distribution of the 2005 West Off Fukuoka Prefecture Earthquake $(\mathrm{Mj}=7.0)$ using a dense onshore and offshore seismic network, Earth Planets Space, 58, 1605-1610, 2006.

Urabe, T. and S. Tsukada, A workstation-assisted processing system for waveform data from microearthquake networks, Abstracts of Spring Meeting of Seismological Society of Japan, p 70, 1991 (in Japanese).

Waldhauser, F. and W. L. Ellsworth, A double-difference earthquake location algorithm: Method and application to the northern Hayward fault, Bull. Seismol. Soc. Am., 90, 1353-1368, 2000.

Watanabe, H., Determination of earthquake magnitude at regional distance in and near Japan, Zisin 2, 24, 189-200, 1971 (in Japanese).

Wessel, P. and W. H. F. Smith, Free software helps map and display data, EOS Trans. AGU, 72, 441, 1991.

Yamada, M., M. Shinohara, T. Kanazawa, N. Hirata, Y. Kaneda, T. Takanami, H. Mikada, K. Suyehiro, S. Sakai, T. Watanabe, K. Uehira, Y. Murai, N. Takahashi, M. Nishino, K. Mochizuki, T. Sato, E. Araki, R. Hino, K. Uhira, H. Shiobara, and H. Shimizu, Aftershock Distribution of the 2003 Tokachi-oki Earthquake derived from high-dense network of ocean bottom seismographs, Zisin 2, 57, 281-290, 2005 (in Japanese).

Yamada, T., K. Mochizuki, M. Shinohara, T. Kanazawa, A. Kuwano, K. Nakahigashi, R. Hino, K. Uehira, T. Yagi, N. Takeda, and S. Hashimoto, Aftershock observation of the Noto Hanto Earthquake in 2007 using ocean bottom seismometers, Earth Planets Space, 60, 1005-1010, 2008

Yamanaka, Y. and M. Kikuchi, Asperity map along the subduction zone in northeastern Japan inferred from regional seismic data, J. Geophys. Res., 109, B07307, doi:10.1029/2003JB002683, 2004.

Zelt, C. A. and R. B. Smith, Seismic travel time inversion for 2-D crustal velocity structure, Geophys. J. Int., 108, 16-34, 1992.

M. Shinohara (e-mail: mshino@eri.u-tokyo.ac.jp), T. Kanazawa, T. Yamada, K. Nakahigashi, S. Sakai, R. Hino, Y. Murai, A. Yamazaki, K. Obana, Y. Ito, K. Iwakiri, R. Miura, Y. Machida, K. Mochizuki, K. Uehira, M. Tahara, A. Kuwano, S. Amamiya, S. Kodaira, T. Takanami, Y. Kaneda, and T. Iwasaki 